\title{
Genetic variability in jack mackerel Trachurus murphyi Nichols: New SSRs loci and application
}

\section{Variabilidad genetica en jurel (Trachurus murphyi Nichols): Nuevos loci SSRs y aplicación}

\author{
Ricardo Gallegulllos $^{1 *}$, Cristian B. Canales-Aguirre ${ }^{1}$ and Sandra Ferrada ${ }^{1}$ \\ ${ }^{1}$ Laboratorio de Genética y Acuicultura, Departamento de Oceanografía, Universidad de Concepción, Casilla 160-C \\ Concepción, Chile. \\ *E-mail: rgalleg@udec.cl
}

\begin{abstract}
Nine novel microsatellite loci were developed for Trachurus murphyi. These loci were characterized in samples from three sites along the eastern South Pacific Ocean. One of the loci was monomorphic, whereas the rest of the loci had between six and 19 alleles per locus and showed the expected heterozygosity ranging from 0.653 to 0.933 . These loci do not show genetic differentiation among the analyzed sites.
\end{abstract}

\section{RESUMEN}

Nueve nuevos loci microsatélites fueron desarrollados para Trachurus murphyi. Estos loci fueron caracterizados en muestras de tres localidades a lo largo del océano Pacífico suroriental. Uno de los loci fue monomórfico, mientras que para el resto de los loci el número de alelos por locus oscilo entre 6 a 16 y la heterocigosidad esperada entre 0.653 a 0.933 . Estos loci no muestran diferenciación entre las diferentes localidades analizadas.

Jack mackerel (Trachurus murphyi) is a pelagic fish distributed along the eastern Pacific coastline and in the New Zealand Sea (Serra 1991). Due to its economic importance, T. murphyi has been the focus of several studies aiming to resolve its taxonomic status (Poulin et al. 2004) and phylogenetic relationships (Cárdenas et al. 2005) and to assess its population structure. For the latter, several approaches have been used, including morphometrics and meristic life history traits (e.g. Serra 1991), parasites (e.g. Oliva 1999), and genetics (González et al. 1996; Cárdenas et al. 2009). These approaches have revealed from one to three populations along the jack mackerel distribution. Genetic studies using allozymic markers (González et al. 1996), mtDNA, and heterologous microsatellites (Cárdenas et al. 2009) have only shown homogeneity among locations. Although species-specific microsatellite markers for jack mackerel have been described by Canales-Aguirre et al. (2010a), these authors only characterized the markers at one site.

This study describes nine new microsatellite loci isolated from T. murphyi. In addition, we tested these new loci to evaluate the genetic variability among sites in the eastern South Pacific Ocean.
In order to isolate the microsatellite loci, we obtained high-molecular-weight DNA from the muscle tissue of ten individuals of both sexes using a phenol/chloroform method (Sambrook et al. 1989). Microsatellite loci were isolated using an enrichment procedure involving magnetic beads (Jones et al. 2000). DNA was partially digested with a cocktail of seven blunt-end restriction enzymes (HaeIII, StuI, Eco RV, ScaI, Bsr BI, PvuII, Hiu CII). Fragments between 300 and 700 bp were selected by gel extraction and ligated to a 20-bp oligonucleotide adaptor containing a Hind III restriction site at the 5' end. Microsatellite enrichment was achieved using streptavidincoated magnetic beads and 5'-biotinylated TAGA $_{12}$ and $\mathrm{CATC}_{8}$ oligonucleotide probes. The captured molecules were amplified by PCR using a primer complementary to the adaptor, digested with Hind III to remove the adaptor, and ligated into the Hind III site of the pUC19 vector. The plasmids were then electroporated into Escherichia coli DH5. Recombinant clones, identified by blue-white selection, were chosen arbitrarily for sequencing on an ABI 377 using the Big Dye Terminator Cycle Sequencing methodology (Applied Biosystems). Specific primers flanking the identified microsatellite sequences were designed using DesignerPCR v1.03 (Research Genetics) 
(Table 1). The microsatellite loci were amplified in $10-\mu \mathrm{L}$ reactions containing $1 \mathrm{X}$ PCR buffer, $2 \mathrm{mM} \mathrm{MgCl}, 0.2 \mathrm{mM}$ forward primer (fluorescently-labeled), $0.2 \mathrm{mM}$ reverse primer, $200 \mathrm{mM}$ dNTPs, $0.03 \mathrm{U} / \mu \mathrm{L}$ Taq DNA polymerase (Invitrogen ${ }^{\circledR}$ ), and $20 \mathrm{ng}$ genomic DNA template. PCR was performed in a PTC-200 (MJ Research) thermal cycler with the following parameters: $94^{\circ} \mathrm{C}$ for $3 \mathrm{~min}$, followed by 35 cycles of $94{ }^{\circ} \mathrm{C}$ for $40 \mathrm{~s}, 57^{\circ} \mathrm{C}$ for $30 \mathrm{~s}, 72{ }^{\circ} \mathrm{C}$ for $30 \mathrm{~s}$, and a final extension at $72{ }^{\circ} \mathrm{C}$ for $5 \mathrm{~min}$. All loci were successfully amplified under these conditions. The PCR products were analyzed on an ABI 3330 DNA sequencer. Alleles were scored using Peak Scanner ${ }^{\mathrm{TM}}$ software v1.0, with GS500 as the internal size standard.

To assess these loci, we genotyped samples of T. murphyi from three sites in the eastern South Pacific Ocean (Fig. 1). These sites were: 1) Lobos de Afuera Islands, Perú (LA), and 2) Talcahuano (THNO) and 3) Chiloé (CH), Chile. To detect scoring errors due to large allele drop-out, stuttering, and null alleles, we used MICRO-CHECKER v.2.2.3 software (Van Oosterhout et al. 2004). The total number of alleles $(\mathrm{Na})$ and the observed $(\mathrm{Ho})$ and expected heterozygosities $(\mathrm{He})$ were calculated for all microsatellite loci using ARLEQUIN 3.1 (Excoffier et al. 2005). The Hardy-Weinberg equilibrium was tested with ARLEQUIN, and linkage disequilibrium was tested using GENEPOP 3.1 (Raymond \& Rousset 1995). Genetic differentiation was estimated by pairwise Fst and analyses of molecular variance (AMOVA) with ARLEQUIN. The significance of the F-statistics was achieved using 10,000 permutations.

Only the TmurD101 locus was monomorphic (Table 1). The data base did not contain scoring errors such as dropout alleles and stutter bands. Null alleles may be present at the TmurC110 locus, as suggested by the general excess of homozygotes (Table 2). The T. murphyi samples showed high genetic variability of the eight microsatellite loci. The number of alleles per locus ranged from six to 19 (TmurC109a and TmurC12-TmurD5, respectively). He ranged from 0.653 to 0.933 (TmurC109a and TmurD5, respectively) and Ho ranged from 0.143 to 1.000 (Table 2). Significant deviations from the Hardy-Weinberg equilibrium were found for locus TmurC110 at all sites and for locus TmurC12 at Chiloé. No loci were found to be in linkage disequilibrium, suggesting that the eight loci are independent.

TABle 1: Characteristics of the microsatellite loci isolated for T. murphyi. For each marker, we report the locus name, primer sequence, repeat unit, allele size range (bp), and Genbank accession number. Tmur: Trachurus murphyi. Mono $=$ monomorphic locus

TABLA 1: Características de los loci microsatelites aislados para T. murphyi. Reportamos para cada marcador el nombre del locus, la secuencia del primer, el rango del tamaño alelico (pb) y el número de acceso a Genbank. Tmur significa Trachurus murphyi. Mono = locus monomórfico.

\begin{tabular}{|c|c|c|c|c|}
\hline Locus & Primer sequence (5'-3') & Repeat unit & Size range & Genbank Acc \\
\hline \multirow[t]{2}{*}{ TmurC12 } & F: TCTGAACAACTGCTGGAAGAC & $\mathrm{CATC}_{(26)}$ & $128-284$ & GU562609 \\
\hline & R: CTACGCATAGTCCGATCCAC & & & \\
\hline \multirow[t]{2}{*}{ TmurC102 } & F: CAGCAGAGCAGAGTGACTG & $\mathrm{CATC}_{(9)}$ & $219-477$ & GU562612 \\
\hline & R: CACGGATAGGTGGTAAAGC & & & \\
\hline \multirow[t]{2}{*}{ TmurC104 } & F: AGCAGAACCGTCCGATAGTC & TGGA $_{(10)}$ & $157-277$ & GU562613 \\
\hline & R: AGCATCCTGGCAGAAGAATC & & & \\
\hline \multirow[t]{2}{*}{ Tmurc109a } & F: AGCCATCATTGGACTGGC & GATG $_{(10)}$ & $262-350$ & GU562614 \\
\hline & R: AGGCAAGCAAGGTCAAGG & & & \\
\hline \multirow[t]{2}{*}{ TmurC110 } & F: GTTCCCTCTGACTGTAACCTG & GATG $_{(14)}$ & $174-286$ & GU562615 \\
\hline & R: GGTGGTGATGTGATGTGG & & & \\
\hline \multirow[t]{2}{*}{ TmurD5 } & F: GCAGGAGTTACACATTTACAGC & TAGA $_{(23)}$ & $262-458$ & GU562610 \\
\hline & R: AACCAGGTCGCCATAGAG & & & \\
\hline \multirow[t]{2}{*}{ TmurD8 } & F: TAATGCCTTGAGGGTATGTTC & $\mathrm{CTAT}_{(18)}$ & $237-369$ & GU562611 \\
\hline & R: GATGGATGGGTTCTGATAGTG & & & \\
\hline \multirow[t]{2}{*}{ TmurD101 } & F: TAAACCGAGCCGAGTAGAGC & $\operatorname{GACA}_{(15)} \operatorname{GATA}_{(11)}$ & Mono & GU562616 \\
\hline & R: ATTTCCCTTTGGAGCATCCT & & & \\
\hline \multirow[t]{2}{*}{ TmurD112 } & F: CAGAGGACAACTAACGGAGTC & $\mathrm{CTAT}_{(8)}$ & 213-297 & GU562617 \\
\hline & R: GACCTAATGCTGGTTTACAGTG & & & \\
\hline
\end{tabular}


Genetic variability in Trachurus murphyi: Ricardo GaLLEGUILLOS ET AL.

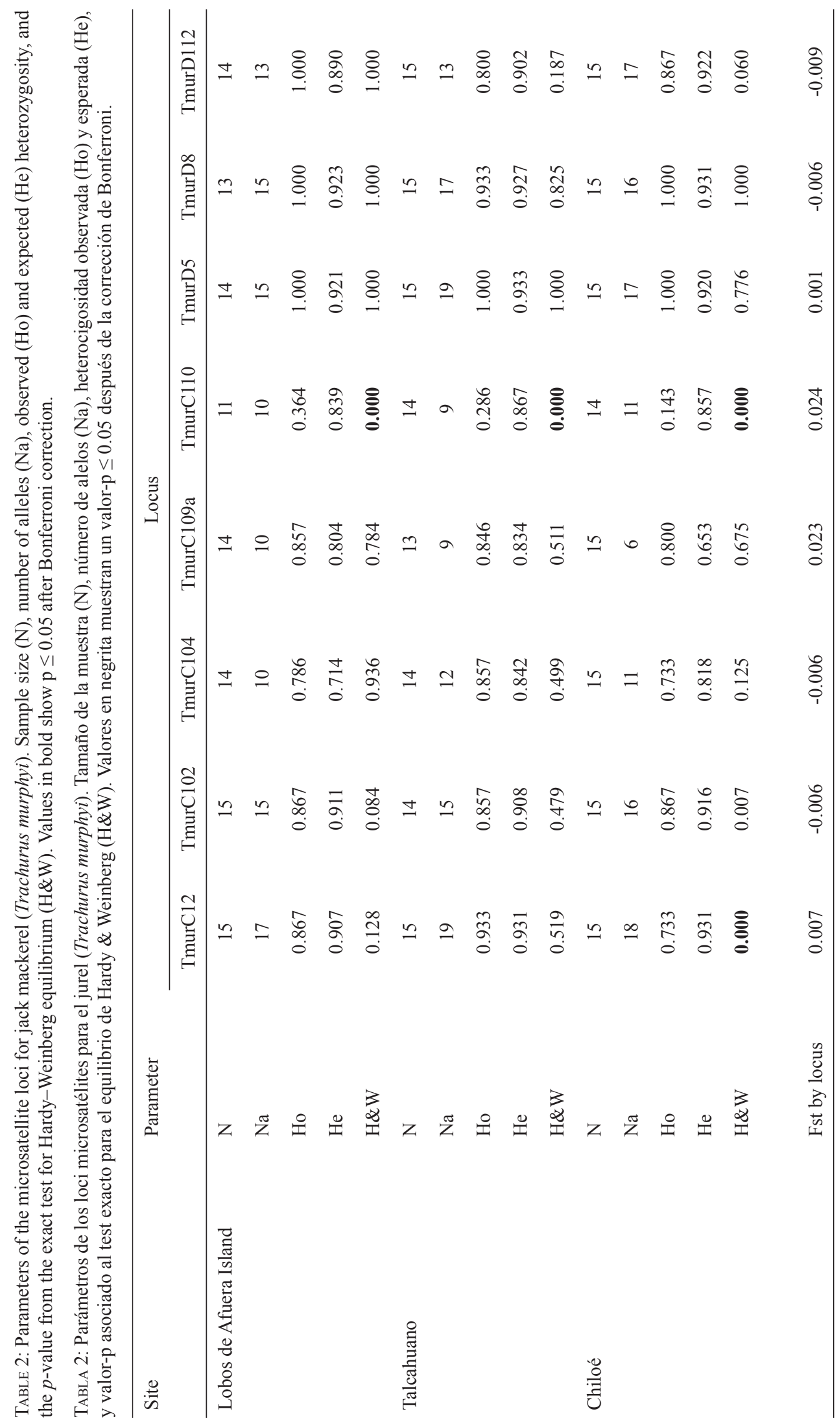




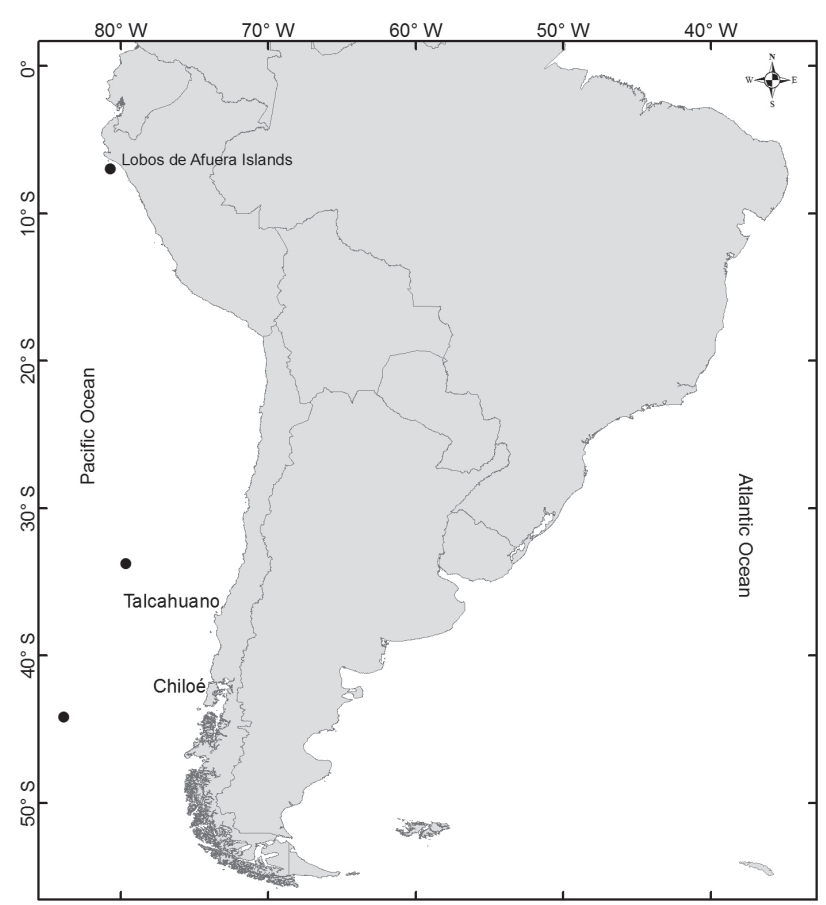

FIgURE 1: Map indicating the T. murphyi sampling sites in the eastern South Pacific Ocean.

Figura 1: Mapa indicando las localidades de muestreo de $T$. murphyi desde el Océano Pacífico sureste.

The AMOVA of the eight microsatellite loci analyzed revealed a non-significant Fst value among the T. murphyi samples $(\mathrm{Fst}=0.003 ; \mathrm{P}=0.591)$. Pairwise Fst tests for genetic differentiation provided non-significant $p$-values among all sample pairs: LA-THNO $=0.004, \mathrm{LA}-\mathrm{CH}=$ 0.001 , THNO-CH $=0.007$, indicating a lack of genetic discontinuities in the analyzed T. murphyi distribution.

The development of new microsatellite loci in T. murphyi to evaluate patterns of genetic variation is necessary for adequate resource conservation and to address other ecological questions. The observed genetic variability is similar to that found by Cárdenas et al. (2009), using heterologous microsatellite loci isolated from Trachurus trachurus (Kasapidis \& Magoulas 2008). Heterologous markers are useful when no species-specific markers are available (e.g. Canales-Aguirre et al. 2010b). Notwithstanding the usefulness of specific microsatellite loci for T. murphyi, those at the population level (as described in CanalesAguirre et al. 2010a) could provide more information on the genetic diversity of the species.

Although the small sample sizes, 15 individuals, used herein are one possible reason for not observing statistically significant differences among the samples studied, our results agree with previous studies (e.g. González et al. 1996; Cárdenas et al. 2009). The characteristics of jack mackerel, such as its large population size (e.g. in 2008, spawning biomass was estimated at $1,934,723$ tons by the daily egg production method according to Ruiz et al. (2009), seasonal migrations between spawning and feeding grounds, and reproductive strategies that facilitate larval dispersal across large geographic distances as well as the lack of obvious physical barriers in the marine environment promote genetic connectivity and the presence of a single reproductive group in this species. This genetic homogeneity is usual in marine fishes (e.g. Canales-Aguirre et al. 2010c) and especially in migratory pelagic species of the Humboldt Current System (e.g. Galleguillos et al. 1997; Ferrada et al. 2002). Ward (2000) reports that mixing rates of $1 \%$ result in genetic homogeneity and a failure to identify stock structure, even if it exists. Notwithstanding a lack of genetic structure may imply the presence of one genetic stock, nevertheless, more than one harvest stocks may exist. For instance, these results are not consistent with morphometric and meristic characteristics and life histories (e.g. Serra 1991), which show more than one population. Incongruence between life history traits and genetics evidence could be to outcome of phenotypic plasticity, more than local adaptation, which implies a genetic component for these differences.

In summary, the new microsatellite loci presented here do not show differences between the three sites along the T. murphyi distribution. On the other hand, these results must be applied with caution due to the small sample sizes used herein. Finally, these loci could be useful for elucidating ecological issues such as genetic structure when dealing with a large sample and the identification of recent reductions in the effective population size, the recent geographic expansion of T. murphyi to New Zealand, and contemporaneous migration along its distribution.

\section{ACKNOWLEDGMENTS}

S. Ferrada and C.B. Canales-Aguirre are students in the Doctoral Program in Systematics and Biodiversity and were supported by UdeC Doctoral Fellowships. This work was funded by project FIP 2007-27.

\section{REFERENCES}

Cárdenas, L., Hernández, C.E., Poulin, E., Magoulas, A., Kornfield, I. OJedA, F.P. 2005. Origin, diversification and historical biogeography of the genus Trachurus (PERCIFORMES: CARANGIDAE). Molecular Phylogenetics and Evolution 35: 496-507

Cárdenas, L., Silva, A.X., Magoulas, A., Cabezas, J., Poulin, E., \&OJEDA, F.P. 2009. Genetic population structure in 
the Chilean jack mackerel, Trachurus murphyi (Nichols) across the South-eastern Pacific Ocean. Fisheries Research 100: 109-115.

Canales-aguirre, C.B., Ferrada, S. \& Gallegulllos, R. 2010a. Isolation and characterization of microsatellite loci for the jack mackerel (Trachurus murphyi Nichols, 1920). Conservation Genetics 11(3): 1235-1237.

Canales-aguirre, C.B., Ferrada, S., Hernández, C.E. \& Galleguillos, R. 2010b. Usefulness of heterologous microsatellites obtained from Genypterus blacodes in species in Genypterus off the southeast Pacific. Gayana 74(1): 74-77.

Canales-aguirre, C.B., Ferrada, S., Hernández, C.E. \& Galleguillos, R. 2010c. Population structure and demographic history of Genypterus blacodes using microsatellite loci. Fisheries Research 106: 102-106

Excoffier, L., Laval, G. \& Schneider, S. 2005. Arlequin ver. 3.0: An integrated software package for population genetics data analysis. Evolutionary Bioinformatics Online 1: 4750 .

Ferrada, S., Hernández, K., Montoya, R. \& Galleguillos, R. 2002. Estudio poblacional del recurso anchoveta (Engraulis ringens Jenyns 1842) (Clupeiformes, Engraulidae), mediante análisis de ADN. Gayana 66 (2): 243-248.

Galleguillos, R., Troncoso, L., Monsalves, J. \& Oyarzún, C. 1997. Diferenciación poblacional en la sardina chilena Strangomera bentincki (Pisces: Clupeidae) análisis genético de variabilidad proteínica. Revista Chilena de Historia Natural 70: 351-361.

González, F., Alay, F., Cabello, J. \& Chávez, R. 1996. Definición de unidad de stock desde el punto de vista genético en el recurso jurel (Trachurus symmetricus murphyi) Nichols, 1920 (Carangidae, Perciforme). Gayana 4:183-196.

Jones, K.C., Levine, K.F. \& BAnKs, J.D. 2000. DNA-based genetic markers in black-tailed and mule deer for forensic applications. California Fish and Game 86: 115-126.

Kasapidis, P. \& Magoulas, A. 2008. Development and application of microsatellite markers to address the population structure of the horse mackerel Trachurus trachurus. Fisheries Research 89: 132-135.

Oliva, M. 1999. Metazoan Parasites of the jack mackerel Trachurus murphyi Nichols, 1920 (Teleostei, Carangidae) in a latitudinal gradient from South America (Chile and Perú). Parasites 6 (3): 223-230.

Poulin, E., Cárdenas, L., Hernández, C.E., Kornfield, I. OJeda, F.P. 2004. Resolution of the taxonomic status of Chilean and Californian jack mackerel using mitochondrial DNA sequence. Journal of Fish Biology 65: 1160-1164.

Raymond, M. \& Rousset, F. 1995. GENEPOP (version 1.2): population genetics software for exact tests and ecumenicism. Journal of Heredity 86: 248-249.

Ruiz, P., A. Sepúlveda, L. Cubillos, C. Oyarzún \& J. Chong 2009. Reproductive parameters and spawning biomass of Chilean jack mackerel (Trachurus murphyi), in 19992008, determined by the daily egg production method. Eighth International Meeting: SWG: Jack Mackerel SubGroup. 11pp

Sambrook, J., Fritsch, E. \& Maniatis, T. 1989. Molecular cloning: a laboratory manual, 2nd edn. Cold Spring Harbor Laboratory Press, USA.

SERRA, J.R. 1991. Important life history aspects of the Chilean jack mackerel, Trachurus symmetricus murphyi. Investigacion Pesquera 36: 67-83.

Van Oosterhout, C., Hutchinson, W.F., Wills, D.P.M. \& Shipley, P. 2004. MICRO-CHECKER: software for identifying and correcting genotyping errors in microsatellite data. Molecular Ecology Notes 4: 535-538.

WARD, R.D. 2000 Genetics in fisheries management. Hydrobiologia 420: 191-201.

Recibido: 05.10.10

Aceptado: 23.01.12 